\title{
Numerical Application of a Stick-Slip Control and Experimental Analysis us- ing a Test Rig
}

\author{
Leonardo D. Pereira ${ }^{1, \star}$, Bruno Cayres ${ }^{1,2, \star \star}$, and Hans I. Weber ${ }^{1, \star \star \star}$ \\ ${ }^{1}$ Dept. of Mechanical Engineering, PUC-Rio, Brazil \\ ${ }^{2}$ Dept. of Mechanical Engineering, CEFET/RJ, Brazil
}

\begin{abstract}
Part of the process of exploration and development of an oil field consists of the drilling operations for oil and gas wells. Particularly for deep water and ultra deep water wells, the operation requires the control of a very flexible structure which is subjected to complex boundary conditions such as the nonlinear interactions between drill bit and rock formation and between the drill string and borehole wall. Concerning this complexity, the stick-slip phenomenon is a major component related to the torsional vibration and it can excite both axial and lateral vibrations. With these intentions, this paper has the main goal of confronting the torsional vibration problem over a test rig numerical model using a real-time conventional controller. The system contains two discs in which dry friction torques are applied. Therefore, the dynamical behaviour were analysed with and without controlling strategies.
\end{abstract}

\section{General Introduction}

\subsection{Oilwell drilling and test-rig model overview}

The actual organizational model of oil and gas industry is no longer sustainable with oil prices below $\$ 50$ a barrel. Christopher et al. (2016) [1] describes what they call the "potentially game-changing disruptions that may lead oil and gas companies to rethink their operating models fundamentally". Then, to address the industry challenges, this paper focuses its efforts on modelling conventional drilling operations using a reduced scale set-up model.

Briefly, the drilling process involves rock failure by a rotating drill bit. To rotate this drill bit from the top-end position (surface), the drilling rig's power source is used to turn a rotary table. A mechanism, consisting of master bushing and kelly is used to transmit the rotation from the rotary table (or top drive) to the drill string. The drill string is the subsurface component through which torque is transmitted from the surface to the bottom of the drilling system (downhole). It consists of connected lengths of drill pipes, the bottom hole assembly (BHA), and the drill bit. The BHA is the portion of the drill string between the drill pipe and the drill bit. It is made up, primarily, of drill collars (DC) and heavy weight drill pipe (HWDP).

Previous studies have identified three types of vibrations that may occur during drilling operations: Torsional, Lateral and Axial, as cited in [2-4].

In order to reproduce the phenomena inherent to the torsional vibrations present in the rotating drilling system

\footnotetext{
^e-mail: leopereiradias@yahoo.com.br

$\star \star$ e-mail: bruno.cayres@ cefet-rj.br

$\star \star \star$ e-mail: hans@puc-rio.br
}

a reduced-scale test rig set-up model (shown in Fig. 1) was developed at the PUC-Rio Dynamics and Vibration Laboratory. The set-up model consists of an electrical and a mechanical subsystems. Electrical subsystem represents the drilling rig's power source and the rotary table (or top drive), while the mechanical system represents the drill pipes, BHA and drill bit.

The test rig consists of three degrees of freedom: disc 1 (R1), disc 2 (R2) and the DC-motor inertia. Also, it contains an electric system which provides torque to the mechanical system.

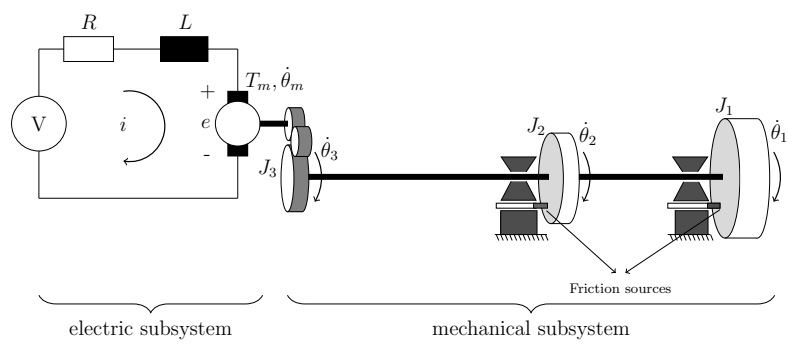

Figure 1. Electromechanical system set-up model.

The electric subsystem is modelled as a voltage source connected in series with a resistor and an inductor, providing torque $T_{m}$. The angular velocity $\Omega_{m}$ imposed by $T_{m}$ is eight times greater than the angular velocity $\Omega_{3}$ transmitted to the mechanical subsystem due to the transmission factor $\eta=8: 1$.

The system presents two resistive torque sources. At disc 1 (R1), the friction means the bit/rock friction interaction. The intermediate friction source (at disc 2) may 
represent a friction raise from the interaction between drill pipes and borehole wall.

\subsection{Motivation and objectives}

Since vibration problems were detected and identified in drilling operations, several approaches have been suggested, both in industry and literature, to model and control these vibrations. Some of these approaches were conducted to the surface system (electric subsystem). Most of them dealt with the torsional behaviour and the suppression of the stick-phase of the stick-slip oscillations [5]. Moreover, the nonlinearity and uncertainty of the system parameter can be modelled in the control design processes. These facts are the motivation of this article.

Therefore, the scope of this paper is to minimize the torsional vibration problem of the test-rig set-up model using a control strategy. Specific objectives address:

- Open-loop analysis of the electrical and mechanical subsystems.

- Application of a control strategy using different velocity inputs in a closed-loop system.

- Control of the torsional vibration considering the nonlinearity due to friction interaction with the first and second inertia.

- Improvement on a developed experimental set-up for future verification and validation of the models.

\subsection{Methodology}

The methodology required to evaluate the performance of the control system is based on five steps [6]:

1. The modelling of the mechanical and mathematical representation of the test-rig set-up model.

2. An open-loop analysis is performed on a simplified model using a linear DC motor and a three degreesof-freedom (DOF) system. In this system, a friction model capable of generating torsional vibrations is proposed acting on the first and second inertia, i.e., Stribeck friction.

3. The closed-loop analysis starts assuming a set of parameters.

4. Two situations are analysed concerning the control strategies:

(a) Only few parameters such as Motor Torque, J3 RPM, and Normal 1 are known.

(b) All the parameters (such as Normal forces and all angular velocities) are known.

Initially, the Proportional and Integral (PI) is the control strategy used in this comparison.

\section{Preliminary concepts}

\subsection{Open-Ioop system}

Generally, there are two open-loop system models: controlled or not controlled. In other words, for an openloop analysis in a drilling system or in the proposed test rig set-up, the process may be equipped with a controller plus an actuator (Fig. 2a) or just with an actuator driven by an input signal Fig. 2b. For the purpose of this paper, the open-loop system will be considered without the controller.

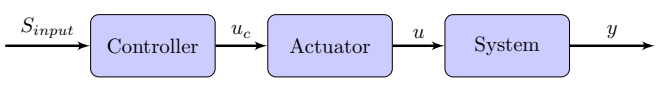

(a) Open-loop system with feedforward control

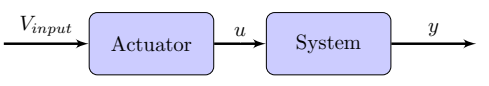

(b) Open-loop system without feedforward control

Figure 2. Block diagrams of open-loop systems.

The $S_{\text {input }}$ is the input signal of the controller in the block diagram of Fig. 2a. The $V_{\text {input }}$ and $u_{c}$ are the voltage input signal of the actuator, the $u$ is the torque input signal of the drilling system. The $y$ is the output angular velocity of the system.

\subsection{Closed-loop system}

For this paper the closed-loop analysis of the test rig set-up will be performed with disturbances and without disturbances. Furthermore, the closed-loop control system, also known as feedback control system, is represented by the block diagram shown in Fig. 3 .

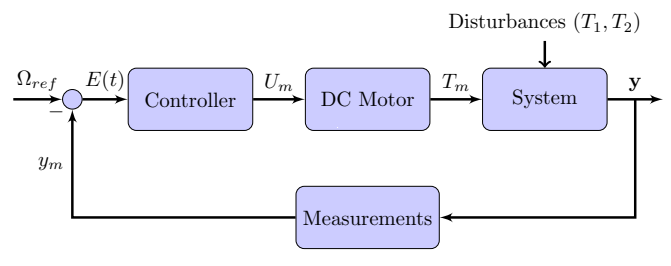

Figure 3. General block diagrams of a closed-loop system.

The $\Omega_{r e f}$ is the reference signal of the system to be compared to the measured angular velocity $y_{m}$ in the block diagram of Fig. 3 and generates the error signal $E(t)$. The $U_{m}$ is the voltage input signal of the actuator, the $T_{m}$ is the torque input signal of test rig set-up. The $\mathbf{y}$ is the output angular velocities of test rig set-up.

\subsection{Automatic control systems}

The control strategy (PI controller) used in the current paper is a well known industrial closed-loop controller, chosen according to their control actions, as explained in more details in [6]. 


\subsubsection{Proportional and integral controller (PI)}

The principle used in the SoftTorque control system (PI controller) is based on the proportional and integral control theory. So, based on the general block diagram of Fig. 3, the mathematical control law has the form:

$$
\mathbf{u}_{\mathbf{c}}(t)=k_{p} e(t)+k_{i} \int_{0}^{t} e(t) d t
$$

where $u_{c}$ is the control signal, $y_{m}$ is the controlled variable, $r$ is the manipulated variable and $e(t)$ is the control error $\left(e(t)=\left[r(t)-y_{m}(t)\right]\right) \cdot k_{p}$ is the proportional gain. $k_{i}$ is the integral gain and can be represented as $k_{i}=\frac{k_{p}}{T_{i}} . T_{i}$ is the integral time constant.

\section{Mathematical modelling of the test rig set-up model}

A simple schematic of the reduced scale test rig set-up model is illustrated in Fig. 1.

In this case, the torsional set-up model is divided in two dynamic subsystems: the electrical system and the mechanical system. The first part (electrical), is represented by a DC motor, delivering torque on the third inertia. The motor dynamics has a considerable impact on the full dynamical behaviour. On the other hand, the mechanical part consists of three inertia. Both subsystems are physically connected to perform the torsional dynamics and will be investigated separately.

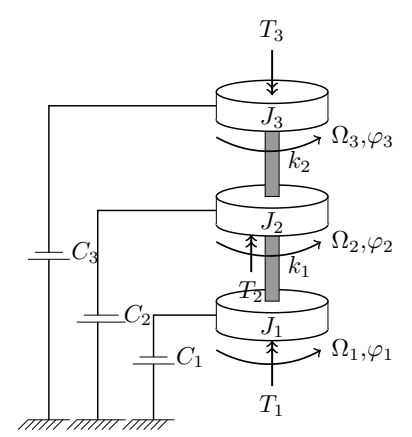

Figure 4. A test rig set-up modelled as a torsional pendulum.

The corresponding equations of motion of the test rig set-up model are represented by the model of torsional dynamics in Eq. 2.

$$
\begin{gathered}
{\left[\begin{array}{ccc}
J_{1} & 0 & 0 \\
0 & J_{2} & 0 \\
0 & 0 & J_{3}
\end{array}\right]\left[\begin{array}{c}
\dot{\Omega}_{1} \\
\dot{\Omega}_{2} \\
\dot{\Omega}_{3}
\end{array}\right]+\left[\begin{array}{ccc}
C_{1} & 0 & 0 \\
0 & C_{2} & 0 \\
0 & 0 & C_{3}
\end{array}\right]\left[\begin{array}{c}
\Omega_{1} \\
\Omega_{2} \\
\Omega_{3}
\end{array}\right]+} \\
+\left[\begin{array}{ccc}
k_{1} & -k_{1} & 0 \\
-k_{1} & k_{1}+k_{2} & -k_{2} \\
0 & -k_{2} & k_{2}
\end{array}\right]\left[\begin{array}{c}
\varphi_{1} \\
\varphi_{2} \\
\varphi_{3}
\end{array}\right]=\left[\begin{array}{c}
-T_{1} \\
-T_{2} \\
T_{3}
\end{array}\right]
\end{gathered}
$$

where $\varphi_{1}, \varphi_{2}$ and $\varphi_{3}$ are the angular displacements of the three discs, $\Omega_{1}, \Omega_{2}$ and $\Omega_{3}$ are the angular velocities measured at the three discs. $J_{1}, J_{2}$ and $J_{3}$ are the equivalent mass moment of inertia of the three discs. $C_{1}, C_{2}$ and $C_{3}$ are the equivalent viscous damping coefficients, $k_{1}$ and $k_{2}$ is the equivalent torsional stiffness of the wire, and $T_{1}$ and $T_{2}$ are the nonlinear functions representing the resistive torque at discs 1 and 2. $T_{3}$ is the supplied torque to the mechanical system.

The behaviour of the DC electronic motor has its dynamical principles represented by two linear models: (1) the mechanical equation of free-body diagram of the rotor, and (2) the electric circuit equation of the armature.

The equation of motion of the motor dynamics is presented as:

$$
\begin{gathered}
L \dot{I}+R I+V_{e m f}=U_{m} \\
V_{e m f}=k_{e} \eta \Omega_{3} \\
T_{m}=k_{t} I-C_{m} \eta \Omega_{3}-T_{f f}-J_{m} \eta \Omega_{3}
\end{gathered}
$$

where $T_{3}=\eta T_{m}$ due to the gearbox factor. $I$ is defined as armature current, $R$ and $L$ are electrical resistance and electrical inductance, respectively. $U_{m}$ is the motor input voltage. $V_{e m f}$ represents the back-electromotive force (back-emf) related to the angular velocity $\Omega_{3} . k_{e}$ and $k_{t}$ parameters are respectively the electromotive force constant and the motor torque constant. $T_{f f}$ represents a internal friction torque of the DC motor.

\subsection{Friction torque modelling}

For this reason, the Eq. 6 describes how the resistive torque at the drill bit is modelled based on the friction law presented in $[7,8]$.

$$
T_{i}=N_{i} r_{i}\left[\mu_{k}+\left(\mu_{s}-\mu_{k}\right) \cdot e^{-v b\left|\Omega_{i}\right|}\right] \cdot \operatorname{sign}\left(\Omega_{i}\right)
$$

where $i=1,2, N_{i}$ is the normal force, also constant in the model, and $r_{i}$ is the distance between the centre of the disc and the normal contact point (see Fig. 1). $\mu_{s}$ and $\mu_{k}$ are static and kinetic friction coefficient. The friction model curve is illustrated in Fig. 5.

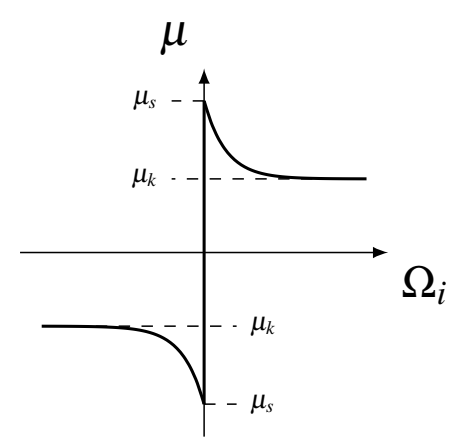

Figure 5. Stribeck friction model.

\section{Stick-slip severity (SSS)}

The Stick-Slip Severity (SSS) is a severity criterion that evaluates the vibration amplitudes in relation to the nominal velocity. Therewith, SSS is performed for the used PI control strategy. In this paper, the SSS may be presented as a $2 \mathrm{D}$ and $3 \mathrm{D}$ grey scale colour-map that plots the 
relation between $N 1$ (normal at R1) and nominal angular velocity (RPM at DC motor), exposing limits where the previous defined torsional vibration (stick-slip) becomes severe according to the criterion.

$$
\mathbf{S S S}=\left(\frac{\Omega_{1}^{\max }-\Omega_{1}^{\min }}{2 \Omega_{\text {ref }}}\right) \cdot 100 \%
$$

where $\Omega_{1}^{\max }$ and $\Omega_{1}^{\min }$ are respectively the maximum and minimum angular velocity of the disc $1 . \Omega_{r e f}$ is the reference angular velocity.

\section{Analysis of the results}

An optimization method is used to evaluate the effectiveness of the open-loop analysis in control design, as presented in the flowchart schematic in Fig. 6. This procedure considers the subsystems separately. Tab. 1 contains the parameters of the test rig set-up.

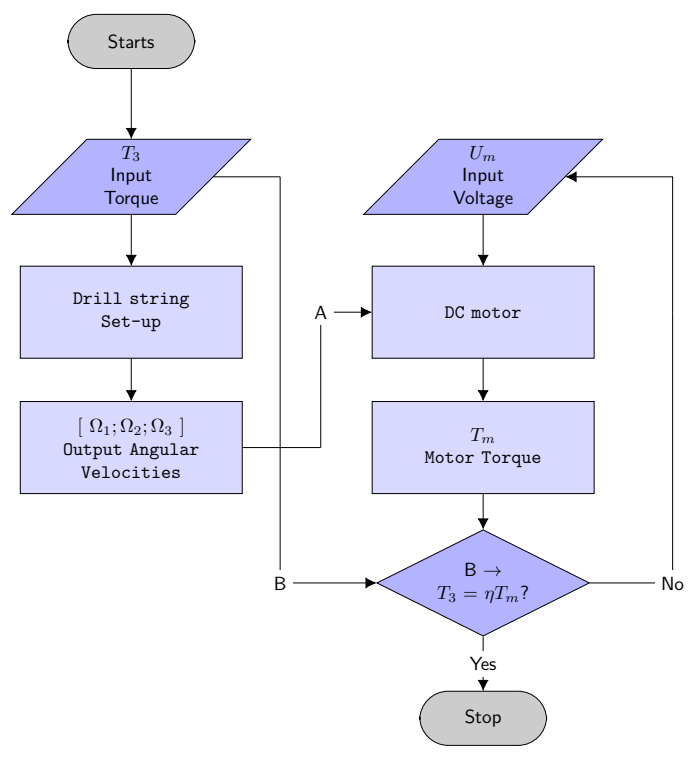

Figure 6. The iterative open-loop flowchart used in the analysis.

Multiple step responses $\left[\Omega_{3}, \Omega_{2}, \Omega_{1}\right]$ of the drill string system are shown in Figs. 7a and 7b. Remembering that in the open-loop analysis there is no need to satisfy any control criteria or to make consistent conclusions about steady state errors, because there is no pre-defined setpoint velocity $\left(\Omega_{r e f}\right)$.

After substituting the parameters of Tab. 1 into the Eq. 2 and 5, a summary of the open-loop angular velocity responses of the test rig set-up and the DC motor systems, given in respect to time when the torque varies, are displayed in Tab. 2. Moreover, for each constant torque from $0.01 \mathrm{~N} \cdot \mathrm{m}$ to $0.30 \mathrm{~N} \cdot \mathrm{m}$ and the associated results, it is defined a Number (Num.) varying from 1 to 15, respectively, in the first column of the Tab. 2.

\subsection{Open-loop results}

A Simulink modelling is designed to simulate the dynamic of the mechanical part of test rig set-up, in other
Table 1. Simulation parameters values.

\begin{tabular}{llll}
\hline \hline Parameter & Description & Value & Unit \\
\hline$J_{1}$ & Disc 1 (R1) & 0.0289 & $\mathrm{~kg} \mathrm{~m}^{2}$ \\
$J_{2}$ & Disc 2 (R2) & 0.0197 & $\mathrm{~kg} \mathrm{~m}^{2}$ \\
$J_{m}$ & DC motor inertia & $0.3710^{-3}$ & $\mathrm{~kg} \mathrm{~m}$ \\
$C_{1}$ & R1 damping & 0.0134 & $\mathrm{Nms} / \mathrm{rad}$ \\
$C_{2}$ & R2 damping & 0.0067 & $\mathrm{Nms} / \mathrm{rad}$ \\
$k_{1}$ & R1-R2 stiffness & 0.6441 & $\mathrm{Nm} / \mathrm{rad}$ \\
$k_{2}$ & R2-R3 stiffness & 0.1762 & $\mathrm{Nm} / \mathrm{rad}$ \\
$R$ & Electrical resistance & 0.33 & $\mathrm{Ohm}$ \\
$L_{2}$ & Electrical inductance & $1.110^{-3}$ & $\mathrm{H}$ \\
$k_{e}$ & Electromotive force constant & $6.0210^{-2}$ & $\mathrm{~V} / \mathrm{rad} / \mathrm{s}$ \\
$k_{t}$ & Motor torque constant & 0.12 & $\mathrm{Nm} / \mathrm{Amp}$ \\
$C_{m}$ & Motor speed constant & $1.9110^{-4}$ & $\mathrm{Nms} / \mathrm{rad}$ \\
$T_{f}$ & Internal friction torque & 0.1 & $\mathrm{Nm}$ \\
$\eta$ & Transmission factor & 8 & - \\
$r_{1}$ & N1 contact point & 0.047 & $\mathrm{~m}$ \\
$r_{2}$ & N2 contact point & 0.047 & $\mathrm{~m}$ \\
$\mu_{s}$ & Static coefficient & 0.461 & - \\
$\mu_{k}$ & kinetic coefficient & 0.370 & - \\
$v_{b}$ & velocity weakening parameter & 1.5 & - \\
$k_{i}$ & integral gain & 1.4891 & - \\
$k_{p}$ & proportional gain & 0.4408 & - \\
\hline \hline
\end{tabular}

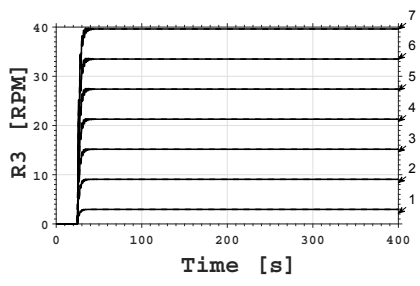

(a) $(0.01 N \cdot m-0.13 N \cdot m)$

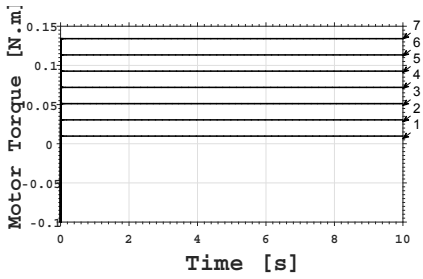

(c) $(0.01 N \cdot m-0.13 N \cdot m)$

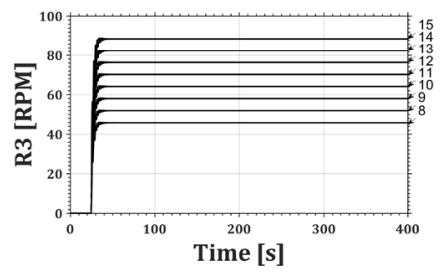

(b) $(0.155 N \cdot m-0.30 N \cdot m)$

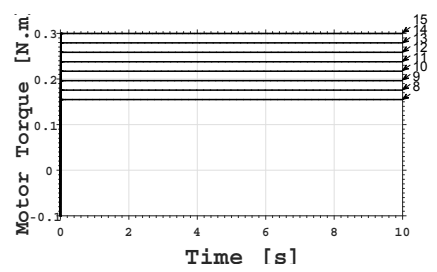

(d) $(0.155 N \cdot m-0.30 N \cdot m)$
Figure 7. Angular velocity and torque responses.

words, without a DC motor actuator. The simulations are performed to evaluate the system behaviour when a range of input torques are disturbed by a set of N1 and N2. The white zone indicates the zone where an input torque is effective to keep the angular velocity at a constant value. The black zone indicates the zone where the input torque 
Table 2. Test rig set-up and DC Motor open-loop results.

\begin{tabular}{|c|c|c|c|}
\hline \multicolumn{3}{|c|}{ Discs 1 and 2} & DC Motor \\
\hline Num. & $T_{3}^{\text {input }}$ & {$\left[\Omega_{1} \& \Omega_{2}\right]^{\text {settled }}$} & $U_{m}$ \\
\hline 1 & $0.0100 N \cdot \mathrm{m}$ & $2.9499 \mathrm{rpm}$ & $0.1865 \mathrm{~V}$ \\
\hline 2 & $0.0307 \mathrm{~N} \cdot \mathrm{m}$ & $9.0605 \mathrm{rpm}$ & $0.5018 \mathrm{~V}$ \\
\hline 3 & $0.0514 N \cdot \mathrm{m}$ & $15.1710 \mathrm{rpm}$ & $0.8171 \mathrm{~V}$ \\
\hline 4 & $0.0721 \mathrm{~N} \cdot \mathrm{m}$ & $21.2816 \mathrm{rpm}$ & $1.1324 \mathrm{~V}$ \\
\hline 5 & $0.0929 \mathrm{~N} \cdot \mathrm{m}$ & $27.3921 \mathrm{rpm}$ & $1.4477 \mathrm{~V}$ \\
\hline 6 & $0.1136 \mathrm{~N} \cdot \mathrm{m}$ & $33.5026 \mathrm{rpm}$ & $1.7630 \mathrm{~V}$ \\
\hline 7 & $0.1343 \mathrm{~N} \cdot \mathrm{m}$ & $39.6132 \mathrm{rpm}$ & $2.0783 \mathrm{~V}$ \\
\hline 8 & $0.1550 \mathrm{~N} \cdot \mathrm{m}$ & $45.7237 \mathrm{rpm}$ & $2.3936 \mathrm{~V}$ \\
\hline 9 & $0.1757 N \cdot \mathrm{m}$ & $51.8343 \mathrm{rpm}$ & $2.7089 \mathrm{~V}$ \\
\hline 10 & $0.1964 N \cdot \mathrm{m}$ & $57.9448 \mathrm{rpm}$ & $3.0242 \mathrm{~V}$ \\
\hline 11 & $0.2171 \mathrm{~N} \cdot \mathrm{m}$ & $64.0554 \mathrm{rpm}$ & $3.3395 \mathrm{~V}$ \\
\hline 12 & $0.2379 \mathrm{~N} \cdot \mathrm{m}$ & $70.1659 \mathrm{rpm}$ & $3.6548 \mathrm{~V}$ \\
\hline 13 & $0.2586 \mathrm{~N} \cdot \mathrm{m}$ & $76.2765 \mathrm{rpm}$ & $3.9701 \mathrm{~V}$ \\
\hline 14 & $0.2793 N \cdot \mathrm{m}$ & $82.3870 \mathrm{rpm}$ & $4.2854 \mathrm{~V}$ \\
\hline 15 & $0.3000 \mathrm{~N} \cdot \mathrm{m}$ & $88.4976 \mathrm{rpm}$ & $4.6006 \mathrm{~V}$ \\
\hline
\end{tabular}

is not sufficient to suppress the resistive torque generated by the normal forces (N1 and N2).

The Hopf supercritical bifurcation diagrams of the test rig system are assumed in a non-controlled system for a set of N1 and N2 $0 \mathrm{~N}$ and $10 \mathrm{~N}$, as illustrated in Figs. 8a and $8 \mathrm{~b}$ and Figs. $9 \mathrm{a}$ and $9 \mathrm{~b}$, respectively.

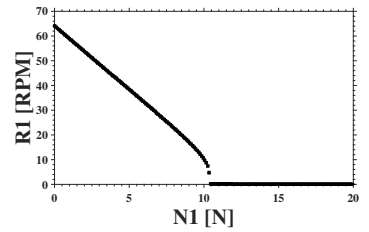

(a) $\Omega_{\text {ref }}=64.05 \mathrm{rpm}$

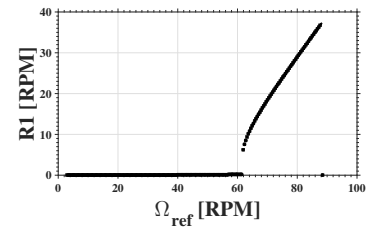

(b) $N 1=10 \mathrm{~N}$
Figure 8. Bifurcation diagrams for $N 2=0 \mathrm{~N}$.

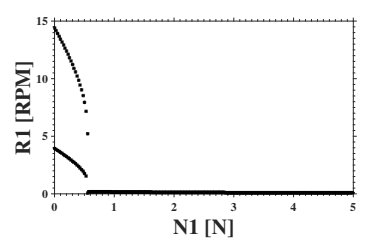

(a) $\Omega_{\text {ref }}=64.05 \mathrm{rpm}$

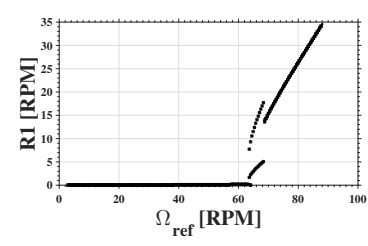

(b) $N 1=0.50 \mathrm{~N}$
Figure 9. Bifurcation diagrams for $N 2=10 \mathrm{~N}$.

\subsection{Closed-loop results: PI controller}

Now, a Simulink modelling is designed to simulate the dynamic test rig set-up with a DC motor actuator. The torsional vibration map of the test rig system when subjected to PI controller is illustrated in Figs. 10a and 10b. It is noticed that the system reaches amplitudes of vibration that are $4 x(200 \%)$ the nominal velocity. The white zone indicates the zone where a PI controller is effective. For best understanding see [9].

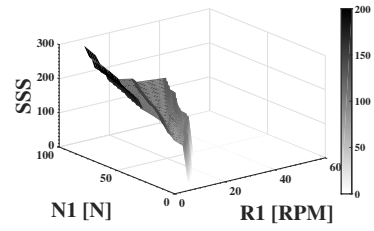

(a) 3D map

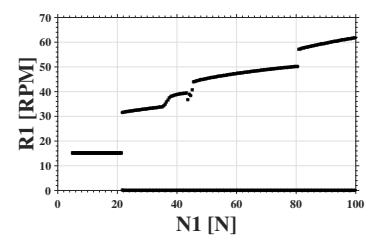

(c) $\Omega_{\text {ref }}=15.17 \mathrm{rpm}$

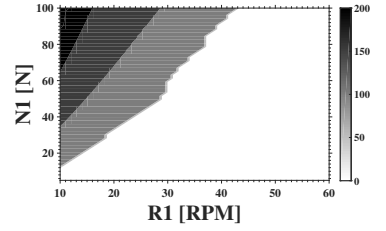

(b) $2 \mathrm{D}$ map

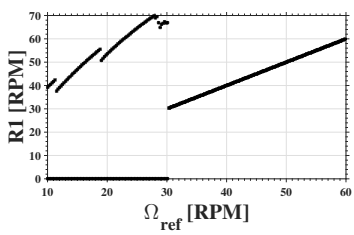

(d) $N 1=60 \mathrm{~N}$
Figure 10. SSS and Bifurcation diagrams for PI $(N 2=0 \mathrm{~N})$.

In this case, it is possible to say (see Fig. 10c) that, for a constant angular velocity $\left(\Omega_{\text {ref }}=15.17 \mathrm{rpm}\right)$, it presents transition region from equilibrium point to periodic solution. It is a Hopf supercritical bifurcation diagram and may show the amplitude of vibration increasing when different $N 1$ are applied to the system PI controller, as illustrated in Fig. 10c. Also, using $\Omega_{\text {ref }}$ as nonlinear control parameter, Fig. 10d, for $N 1=60 N$, the periodic solution becomes equilibrium point around $\Omega_{\text {ref }}=30 \mathrm{rpm}$.

In order to analyse the influence of intermediate friction on the dynamic responses and the effectiveness zone of PI controller, $N 2 \neq 0$, Figs. $11 \mathrm{a}$ and $11 \mathrm{~b}$ present the SSS maps. The vibration zone is clearly increased compared to Figs. 10a and 10b. Also, the bifurcation points have changed observing Figs. 10c and 10d comparing to $11 \mathrm{c}$ and $11 \mathrm{~d}$.

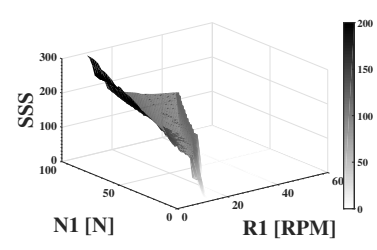

(a) 3D map

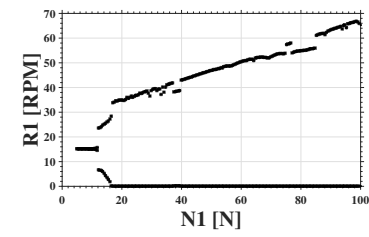

(c) $\Omega_{\text {ref }}=15.17 \mathrm{rpm}$

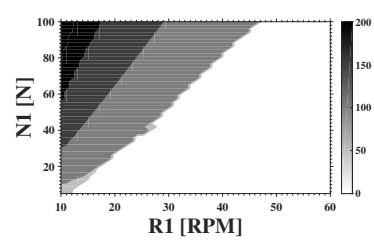

(b) $2 \mathrm{D}$ map

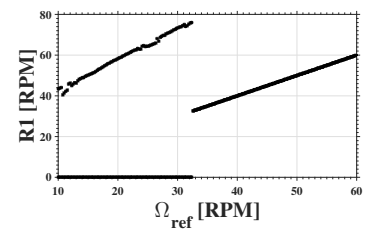

(d) $N 1=60 \mathrm{~N}$
Figure 11. SSS and Bifurcation diagrams for PI $(N 2=10 \mathrm{~N})$. 
Figs. $11 \mathrm{~b}$ and $11 \mathrm{c}$ still show two nonlieanr jumps before $20 \mathrm{rpm}$ when $\mathrm{N1}$ is varied. Following the same reasoning, Fig. 12 illustrates large variations of SSS. However, for all three $N 2$ values, the greater influence occurs for low values of $\Omega_{r e f}$ where it may be observed a decreasing of the effective zone of the PI controller.

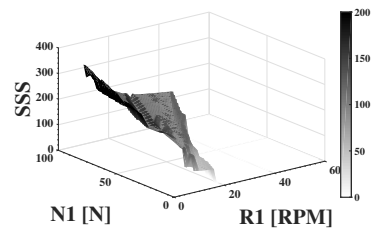

(a) 3D map

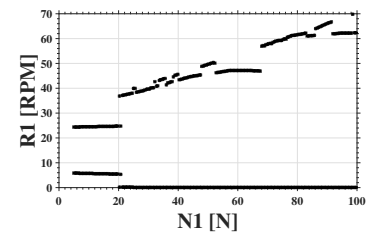

(c) $\Omega_{\text {ref }}=15.17 \mathrm{rpm}$

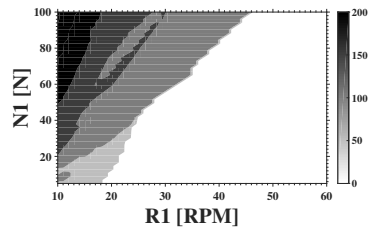

(b) $2 \mathrm{D}$ map

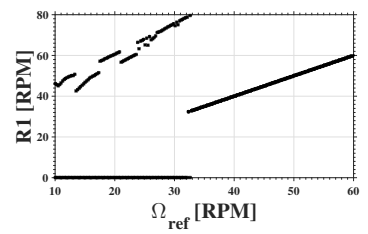

(d) $N 1=60 \mathrm{~N}$
Figure 12. SSS and Bifurcation diagrams for PI $(N 2=20 \mathrm{~N})$.

Finally, a comparison between numerical and experimental values is performed. The system is settled to 30 and $50 \mathrm{rpm}$ and the both transient are observed in Figs. $13 \mathrm{a}$ and $13 \mathrm{~b}$, respectively.

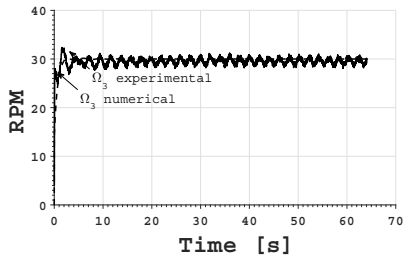

(a) $30 \mathrm{rpm}$

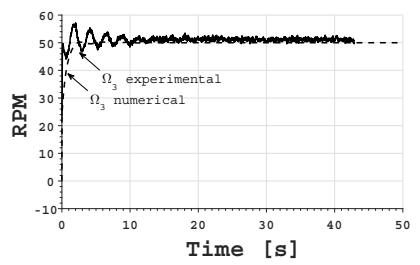

(b) $50 \mathrm{rpm}$
Figure 13. Numerical and Experimental $\Omega_{3}$ comparison.

For this test, both data converge to the settled angular velocity and the step response characteristics of both systems show the following performance indicators (see Tabs. 3 and 4).

\section{Conclusions}

The drilling system provides a myriad of problems to investigate. Controlling torsional vibration of this kind of system is challenging.

It is possible to observe that the PI controller is effective in a certain zone. By varying the intermediate friction torque $T_{2}$ (via $N 2$ ), the controllable zone changes mainly for low nominal velocities $\Omega_{r e f}$. PI controller has proven to be very ineffective when the system is in torsional vibration. This is because PI controller is a linear controller,
Table 3. Attributes of the test rig set-up. (30 rpm).

\begin{tabular}{rcc}
\hline \hline Attributes & $\Omega_{3}$ Exp. & $\Omega_{3}$ Num. \\
\hline Rise time $\left[\tau_{r}(s)\right]$ & 1.3207 & 1.4841 \\
Settling time $\left[\tau_{s}(s)\right]$ & $\mathrm{N} / \mathrm{A}$ & 1.8692 \\
Peak time $\left[\tau_{p}(s)\right]$ & 1.9462 & 6.0147 \\
Overshoot $[\%$ OS] & 8.9790 & 0.4908 \\
\hline \hline
\end{tabular}

Table 4. Attributes of the test rig set-up. (50 rpm).

\begin{tabular}{rcc}
\hline \hline Attributes & $\Omega_{3}$ Exp. & $\Omega_{3}$ Num. \\
\hline Rise time $\left[\tau_{r}(s)\right]$ & 1.2246 & 1.4793 \\
Settling time $\left[\tau_{s}(s)\right]$ & N/A & 1.8646 \\
Peak time $\left[\tau_{p}(s)\right]$ & 1.8598 & 6.0165 \\
Overshoot $[\%$ OS $]$ & 12.0614 & 0.4919 \\
\hline
\end{tabular}

but also has shown to restrain torsional vibrations for high nominal velocities.

In a first approach, this methodology is important to understand the test rig system and which controller (or combination of controllers) may be applied in experimental analysis.

\section{References}

[1] C. Handscom, S. Sharabur, J. Woxholth, The oil and gas organization of the future, Online; accessed 08Feb (2017), http://www.mckinsey.com/industries/oiland-gas/our-insights/the-oil-and-gas-organization-ofthe-future

[2] F. Abdulgalil, H. Siguerdidjane, PID Based on Sliding Mode Control for Rotary Drilling System, in IEEE/EUROCON The International Conference on "Computer as a Tool" (Serbia \& Montenegro, Belgrade, 2005), Vol. 2, pp. 262-265

[3] A.H. Suleiman, Tech. rep., Universiti Teknologi MARA (UiTM), Selangor Darul Ehsan, Malaysia (2006)

[4] E.M. Navarro-López, Bit-sticking Phenomena in a Multidegree-of-freedom Controlled drill string, in Exploration $\mathcal{E}$ Production (2010), Vol. 8 of 2, pp. 7075

[5] M.B. Saldivar, S. Mondié, J.J. Loiseau, Reducing Stick-Slip Oscillations in Oilwell drill strings, in 6 th International Conference on Electrical Engineering, Computing Science and Automatic Control (Toluca de Lerdo, Mexico, 2009), pp. 1-6

[6] L.D. Pereira, M.Sc. Thesis, Pontifícia Universidade Catolica do Rio de Janeiro, Rio de Janeiro, Brazil (2017)

[7] T.G.M. Vromen, Ph.D. thesis, Eindhoven University of Technology, Eindhoven, The Netherlands (2015)

[8] J. Rudat, D. Dashevskiy, Development of an innovative model-based stick/slip control system, in SPE/IADC Drilling Conference and Exhibition (Society of Petroleum Engineers, 2011)

[9] B. Cayres, M.Sc. Thesis, Pontifícia Universidade Catolica do Rio de Janeiro, Rio de Janeiro, Brazil (2013) 